\title{
Complications of Vehicular-Related Injuries: A Scoping Review of
}

\section{Literature}

\author{
Pooria Sarrami, ${ }^{1,2,}{ }^{*}$ Rafael Ekmejian, ${ }^{1}$ Justine M Naylor, ${ }^{1,3}$ and Ian A Harris ${ }^{1,3}$ \\ ${ }^{1}$ South Western Sydney Clinical School, University of New South Wales, Sydney, Australia \\ ${ }^{2}$ Institute of Trauma and Injury Management, New South Wales Agency for Clinical Innovation, Sydney, Australia \\ ${ }^{3}$ South Western Sydney Local Health District, Liverpool Hospital, Liverpool, Australia \\ "Corresponding author: Pooria Sarrami, Institute of Trauma and Injury Management, New South Wales Agency for Clinical Innovation, Level 4, Sage Building, 67 Albert Avenue, \\ Chatswood NSW 2067, Sydney, Australia. Tel: +61-294644679, Fax: +61-294644728, E-mail: pooria.sarrami@health.nsw.gov.au
}

Received 2016 February 25; Revised 2016 June 27; Accepted 2016 July 19.

\begin{abstract}
Context: Complications of vehicular-related trauma contribute to the overall morbidity, and ultimately the costs, of road accidents. However, direct evidence on the burden of complications of vehicular-related trauma injuries is not directly explored. This scoping review aims to provide a summary of the relevant literature on the most significant acute complications and consequences of trauma caused by motor vehicle accidents or similar mechanisms.

Evidence Acquisition: Multiple electronic databases, as well as grey literature, were explored. Studies were included in this scoping review if they evaluated adult patients with acute complications of traumatic injury caused by motor vehicle trauma or similar mechanisms.

Results: Trauma-related complications contribute to increasing mortality of patients. Complications of traumatic injuries are also the main cause of patients' readmission to hospitals. Various studies report the rate of high-grade complications around 10\%, but the overall rate of complications, ignoring severity, is approximately 60\%. Depending on the surveyed population, different complications are identified as the most prevalent, but pneumonia is identified as the most prevalent complication in the majority of studies. The most important factors predicting the occurrence of complications in trauma patients are older age and poor Glasgow coma scale.

Conclusions: Complications of trauma-related injuries are significant factors affecting the outcome of patients. There has been limited research directly exploring this topic, possibly due to the difficulty of undertaking such studies. A particularly important research topic is the prevention and management of complications in elderly trauma patients with comorbidities. In conclusion, complications of trauma related injuries are significant considerations for clinical practice and research.
\end{abstract}

Keywords: Complications, Trauma, Vehicular Trauma

\section{Context}

Road traffic crash casualties impose considerable economic costs to societies (1). Costs of road traffic crash casualties include medical and rehabilitation, long-term care, labour in the workplace and quality of life (1). Complications secondary to vehicular-related trauma contribute to these costs.

Although each particular complication has its own specific definition (2), in this paper we broadly consider complications as undesirable and unexpected adverse health events happening for patients after the initial injury. Trauma patients may have higher rates of complications in comparison with other patients who undergo general surgery (3). Various types of complications are reported in trauma patients, such as: myocardial infarction, pulmonary embolism, renal failure, sepsis, pneumonia, urinary tract infection and wound disruption (3). The reason that trauma patients could be susceptible to compli- cations might be related to physiological or immunologic effects of trauma and high risk cares such as mechanical ventilation and long-term immobilisation (4).

Complications of trauma-related injuries are associated with many variables, as illustrated in Figure 1. There are many studies that have explored the relationship of particular elements with each other, for example, the association between a particular risk factor with a particular injury; or a particular complication in patients with a specific injury. However, despite all the individual studies, this is the first review to provide a summary of the relevant literature on the most significant acute complications and consequences of trauma caused by motor vehicle accidents or similar mechanisms by finding the best evidence for answering the following questions: What is the importance of complications in trauma patients? How common are complications in trauma patients? What are the most common complications? And which patients are more at risk for complications? 


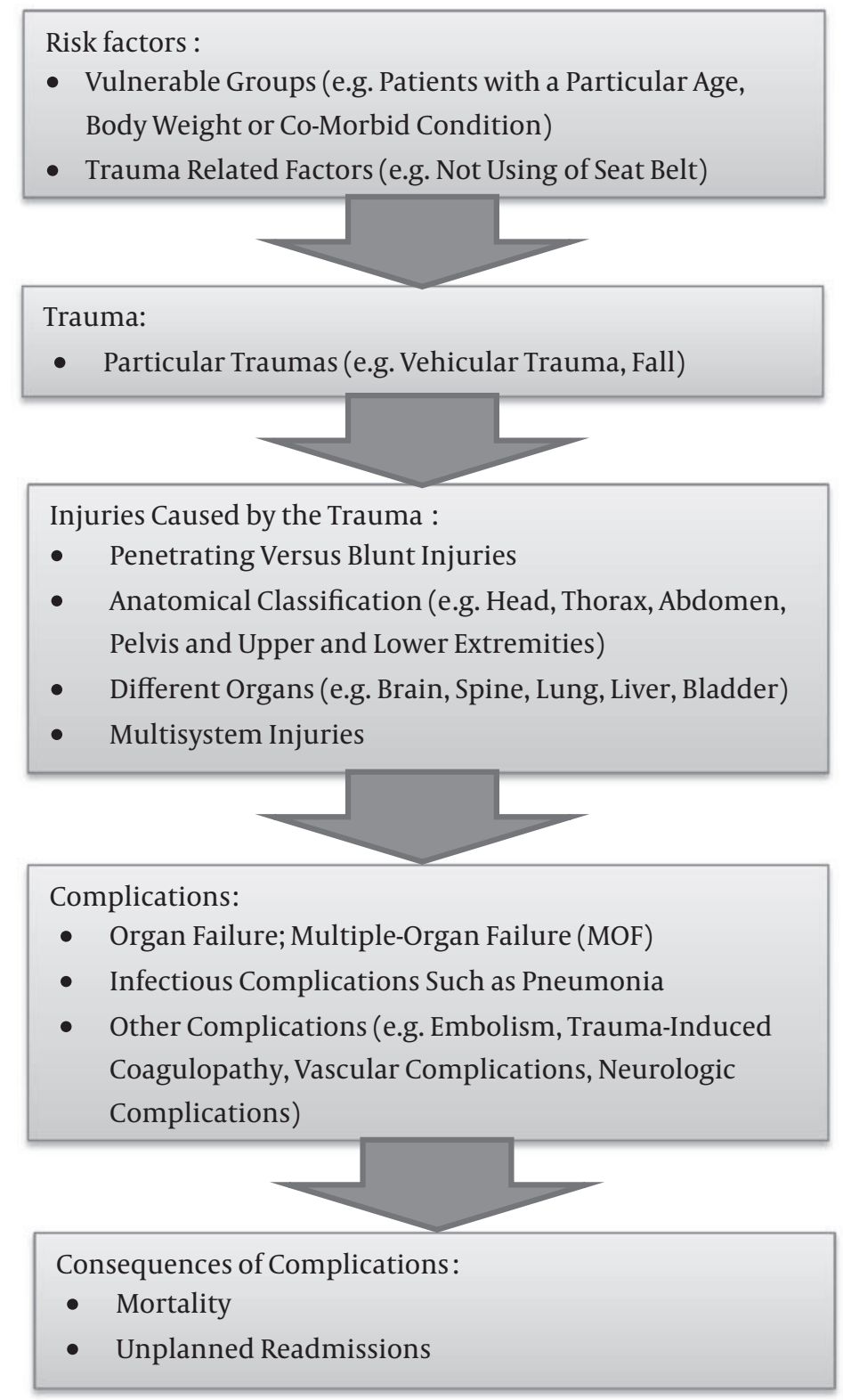

Figure 1. Illustration of Various Factors Associated With Complications of Trauma-Related Injuries

\section{Evidence Acquisition}

This is a scoping review on complications of motor vehicle trauma-related injuries. A scoping review is an evolving literature review methodology $(5,6)$, which is transparent and aims to map the literature and address broad research questions on a topic (5-7). Mapping the literature is an action that provide background information necessary for upcoming projects (8); identifying concepts, gaps, strategies and barriers (9). Therefore, scoping reviews of- fer a broad view of the material available on a topic, rather than the more focused picture normally provided by a systematic review (7).

Medline was searched using the following medical subject headings and phrases: wounds and injuries/[complications]; wounds and injuries/[epidemiology]; motor vehicle accident; (vehicle accident or traffic accident); (Australia and trauma). This search was restricted to publications in English and 
studies on adult humans (19 plus years) in the past five years (2009 - 2014). In addition, other sources such as Google Scholar, the Cochrane library, online websites of governmental organisations and seminal books were also searched with no time limitations. In addition, queries were made from a number of key researchers. Criteria for considering studies for this scoping review were: adult patients from developed countries; target conditions were acute complications (up to three months post incident) of traumatic injury caused by motor vehicle trauma or similar mechanisms. Data from disparate populations, psychological and mental health issues, and gunshot and military trauma were excluded.

\section{Results}

Initial search identified 2,731 items. Using titles and abstracts, 2,695 items were excluded. Full texts were obtained for 36 papers and 21 were finally included in the study. The identified studies are presented according to the review's research questions and are also introduced in Tables 1 - 4 . Presenting papers in different tables assisted focusing on different elements of the studies that are more relevant to each research question. Some studies are included in more than one tabulation. The following result section is structured based on the four research questions.

\subsection{What is the Importance of Complications in Trauma Pa-} tients?

Trauma-related complications contribute to increasing mortality of patients $(4,10,11)$. It has been documented that complications such as organ failure (12), multipleorgan failure (MOF) $(13,14)$ and trauma-induced coagulopathy (15) are associated with higher mortality of trauma patients. The rate of mortality increases by the number of organ system failures (12-14). Organ failure and MOF have been identified in 5\% - 15\% of trauma patients; the higher incidences are related to patients with more severe injuries $(12,14,16)$.

Complications of trauma injuries are also the main cause of 30-day readmission to hospital. It is reported that $30 \%$ of readmissions of trauma patients are due to complications and in comparison with non-trauma patients, trauma patients are ten times more likely to be re-admitted due to complications (17). The most frequent complications leading to readmission of trauma patients include anastomosis haemorrhage (4.3\%), orthopaedic wound infection (3.0\%), pneumonia (3.0\%), iatrogenic congestive heart failure (2.4\%) and loss of bony reduction/fixation (2.0\%) (17).
Re-admissions to the intensive care unit (ICU) are also problematic. The majority (71.6\%) of unplanned readmissions of trauma patients to ICU happen during the 72 hours after ICU discharge (18). The most common complications that lead to readmission to ICU are respiratory, bleeding, cardiovascular, neurologic, non-respiratory infection and pulmonary embolism. Pneumonia is the most common complication that leads to ICU admission of trauma patients $(18,19)$.

\subsection{How Common are Complications in Trauma Patients?}

Patients in trauma centers are more likely to have a complication compared to patients in non-trauma centers (2). Overall rate of complications (considering all different types of complication) can be as high as 60\% (4), however, if considering more severe complications, the rate is reported to be approximately $10 \%(4,10,20)$. The rate of complications are higher in patients with more severe injuries, such as those with multi-trauma (4) or patients admitted to ICU (19). Particular types of complications have different rates (Table 2 ), for example infectious complications have been identified in $5.7 \%$ in patients with vehicular trauma (21).

\subsection{What Are the Most Common Complications}

Depending on the surveyed population, different items are identified as the most common complications (Table3). For example, among the patients with spinal cord injuries, the most common infectious complications are urinary tract infections and pneumonia; while after colon injuries, the most common infectious complications are sepsis and surgical site infections (21). Pneumonia is identified as the most prevalent complication in the majority of studies $(2,4,18-20,22)$. The other complications frequently found are urinary tract infections and other types of infections $(2,4,17,18,20)$.

\subsection{Which Patients are More at Risk for Complications?}

Complications can be predicted based on various factors (see Table 4). The most important factors predicting the occurrence of complications in trauma patients are older age, and poor Glasgow coma scale $(2,25)$. In addition, elderly population are not only more vulnerable to complications, but also have higher mortality following posttrauma complications $(14,22)$. Injury-type is also related to risk of complication. Patients with particular forms of injuries are prone to complications, for example, $70 \%$ of patients with spinal cord injury are reported to have at least one complication (23). Pre-existing conditions are other factors that increase mortality in trauma patients (26). In 
Table 1. Rate of Consequences of Complications in Trauma Patients

\begin{tabular}{|c|c|c|c|c|}
\hline Study & Country of Study & Type of Patients & Evaluated Consequences & Rate of the Consequences, $\%$ \\
\hline Osler et al. 2012 (11) & USA & $\begin{array}{l}\text { Adult patients admitted to } \\
\text { hospitals for traumatic injury }\end{array}$ & Mortality & 2.8 \\
\hline \multirow{2}{*}{ Saltzherr et al. 2010 (4) } & \multirow{2}{*}{ The Netherlands } & \multirow{2}{*}{$\begin{array}{l}\text { Adult patients with } \\
\text { multi-trauma admitted to } \\
\text { level one trauma centers }\end{array}$} & Mortality & 18.8 \\
\hline & & & Readmission & 4 \\
\hline Haas et al. $2011(10)$ & Canada & $\begin{array}{l}\text { Adults patients admitted to } \\
\text { trauma centers for at least } 2 \\
\text { days }\end{array}$ & Mortality & 7.9 \\
\hline Fakhry et al. 2013 (18) & USA & $\begin{array}{l}\text { Adult trauma patients } \\
\text { discharged from ICU }\end{array}$ & Readmission to ICU & 4.8 \\
\hline \multirow{5}{*}{ Moore et al. 2014 (17) } & \multirow{5}{*}{ Canada } & \multirow{5}{*}{$\begin{array}{l}\text { Adults discharged from } \\
\text { trauma centers }\end{array}$} & \multirow{5}{*}{ Unplanned readmission } & Cumulative rates: \\
\hline & & & & At 30 days: 5.9 \\
\hline & & & & At 3 months: 10.9 \\
\hline & & & & At 6 months: 15.5 \\
\hline & & & & At 12 months: 21.1 \\
\hline
\end{tabular}

Table 2. Rate of Specific Complications in Trauma Patients

\begin{tabular}{|c|c|c|c|c|}
\hline Study & Country of Study & Type of Patients & Evaluated Complication & Rate of the Complication, \% \\
\hline Dewar et al. 2009 (13) & Australia & Adult trauma patients admitted to ICU & MOF & 17 \\
\hline Haas et al. $2011(10)$ & Canada & $\begin{array}{l}\text { Adult patients admitted to trauma centers } \\
\text { for at least } 2 \text { days }\end{array}$ & Major complications & 9.6 \\
\hline Fraser et al. $2011(21)$ & USA & Adult vehicular trauma patients & Infectious complications & 5.7 \\
\hline Benns et al. 2012 (12) & USA & Adult patients admitted to trauma centers & Concurrent organ failure & 6.5 \\
\hline Dewar et al. 2013 (14) & Australia & Adult trauma patients admitted to ICU & MOF & 15 \\
\hline Hyllienmark et al. 2013 (19) & Sweden & Adult trauma patients admitted to ICU & Pneumonia & 26 \\
\hline Xu et al. 2013 (15) & China & $\begin{array}{l}\text { Adult patients with severe trauma } \\
\text { admitted to emergency intensive care unit }\end{array}$ & Trauma-induced coagulopathy & 23.3 \\
\hline Vogel et al. 2013 (16) & USA & Adult trauma patients & MOF & 5 \\
\hline
\end{tabular}

addition to the factors related to patients, health care setting is also an influential factor. Patients admitted to centers which provides higher levels of care are more prone to complications, possibly due to accepting more complicated patients and performing more aggressive procedures at these centers $(2,25)$.

It is notable that each complication can have specific risk factors. For example, the likelihood of developing pneumonia after trauma can increase because of seemingly extraneous factors such as having a larger gastric volume at the time of trauma (27), patient's environment before admission (28) and intubation in the field (19). In addition, there are care-related factors that can lead to various complications; for example, the use of pulmonary artery catheter is associated with arrhythmias, cardiac arrests and pulmonary embolism (2).

\section{Conclusions}

Complications of trauma related injuries are significant factors affecting the outcome of patients. In general, despite the importance of complications in the morbidity, mortality and cost of care of trauma patients, there has been limited research directly covering the complicationrelated outcome of vehicular traumas. A reason for the shortage may be the difficulty in undertaking studies on complications as they involve manual handling of medical records and are therefore expensive and limited (11). In this review it was observed that information on the traumarelated complications is not directly discussed in many academic and governmental reports. For example, even though the Australian Bureau of statistics is collecting data on various aspects of injuries, complications are not directly reported (29). Therefore it is difficult to determine 
Table 3. The Most Common Complications in Various Groups of Trauma Patients (Up to Five Items Are Displayed From Each Study)

\begin{tabular}{|c|c|c|c|c|}
\hline Study & Country of Study & Selected Patients & $\begin{array}{c}\text { Evaluated } \\
\text { Complications }\end{array}$ & The Most Prevalent Complications (Rates), \% \\
\hline \multirow{4}{*}{$\begin{array}{l}\text { Holbrook et al. } 2001 \\
(20)\end{array}$} & \multirow{4}{*}{ USA } & \multirow{6}{*}{$\begin{array}{l}\text { Adult patients admitted } \\
\text { to trauma hospitals for } \\
\text { at least } 24 \text { hours }\end{array}$} & \multirow{6}{*}{$\begin{array}{l}\text { In-hospital } \\
\text { complications }\end{array}$} & - Pulmonary (5.8) \\
\hline & & & & - Infections (1.4) \\
\hline & & & & - Gastrointestinal (1.4) \\
\hline & & & & - Vascular (1.0) \\
\hline \multirow{6}{*}{ Ang et al. $2009(2)$} & \multirow{6}{*}{ USA } & & & - Neurologic (1.0) \\
\hline & & & & - Pneumonia (12.0) \\
\hline & & \multirow{4}{*}{$\begin{array}{l}\text { Patients admitted to } \\
\text { Level I trauma centers }\end{array}$} & \multirow{4}{*}{ All complications } & - More than 3 complications (7.9) \\
\hline & & & & - Urinary tract infection (6.3) \\
\hline & & & & - Multi-organ failure (5.5) \\
\hline & & & & - Unplanned ICU visits (4.8) \\
\hline \multirow{4}{*}{$\begin{array}{l}\text { Access Economics } 2009 \\
(23)\end{array}$} & \multirow{4}{*}{ Australia } & \multirow{4}{*}{$\begin{array}{l}\text { Hospitalized adult } \\
\text { patients with spinal cord } \\
\text { injury }\end{array}$} & \multirow{4}{*}{ All complications } & - Urinary tract infections (24.3) \\
\hline & & & & - Other bacterial infections (23.7) \\
\hline & & & & - Pressure ulcer (19.3) \\
\hline & & & & - Disorders of the bladder (17.1) \\
\hline \multirow{7}{*}{ Harris et al. 2009 (24) } & \multirow{6}{*}{ USA } & \multirow{6}{*}{$\begin{array}{l}\text { Adult patients with } \\
\text { limb-threatening lower } \\
\text { extremity traumas }\end{array}$} & \multirow{6}{*}{ All complications } & -Streptococcus/Staphylococcus infection (13.8) \\
\hline & & & & -Wound infections (28.3) \\
\hline & & & & - Non-union of fracture (23.7) \\
\hline & & & & - Wound necrosis/breakdown (8.6) \\
\hline & & & & - Osteomyelitis (7.7) \\
\hline & & & & - Joint arthritis (7.3) \\
\hline & \multirow{4}{*}{ Canada } & \multirow{4}{*}{$\begin{array}{c}\text { Adult patients admitted } \\
\text { to trauma centers for at } \\
\text { least } 2 \text { days }\end{array}$} & \multirow{4}{*}{ Major complications } & - Pneumonia (5.9) \\
\hline \multirow{3}{*}{ Haas et al. $2011(10)$} & & & & - Acute respiratory distress syndrome (2.4) \\
\hline & & & & -Sepsis (1.8) \\
\hline & & & & - Cardiovascular complications (1.8) \\
\hline \multirow{7}{*}{ Fraser et al. 2011 (21) } & \multirow{7}{*}{ USA } & \multirow{7}{*}{$\begin{array}{l}\text { Adult vehicular trauma } \\
\text { patients }\end{array}$} & \multirow{7}{*}{ Infectious complications } & - Renal failure (1.2) \\
\hline & & & & After spinal cord injury: \\
\hline & & & & - Urinary tract infection (11.15) \\
\hline & & & & - Pneumonia (10.46) \\
\hline & & & & After colon injuries: \\
\hline & & & & -Sepsis (9.15) \\
\hline & & & & -Surgical site infection (5.02) \\
\hline \multirow{2}{*}{ Adams et al. $2012(22)$} & \multirow{2}{*}{ USA } & \multirow{2}{*}{ Adult trauma patients } & $\begin{array}{l}\text { End organ } \\
\text { complications }\end{array}$ & $\begin{array}{l}\text { - Pulmonary complications have higher rates } \\
\text { comparing with other end organ complications. } \\
\text { (The reported rate varied among different age } \\
\text { groups). }\end{array}$ \\
\hline & & & Infectious complications & $\begin{array}{l}\text { - Pneumonia has higher rates comparing with } \\
\text { other infectious complications. (The reported rate } \\
\text { varied among different age groups). }\end{array}$ \\
\hline
\end{tabular}

the precise nationwide prevalence of trauma-related complications. Finally, it is notable that age and comorbid conditions are among the factors that can increase the risk of complications. As people are expected to live longer in developed countries, the prevalence of age-related comorbid conditions will also increase. Thus, a particularly impor- 
Table 4. Studies Explored Prediction of Complications

\begin{tabular}{|c|c|c|c|}
\hline Study & Country of Study & Study Methodology & Findings on Predictors of Complications \\
\hline Ang et al. $2009(2)$ & USA & $\begin{array}{l}\text { Analyzing data from } 18 \text { level } 1 \text { trauma centers and } 51 \\
\text { non-trauma centers }\end{array}$ & $\begin{array}{l}\text { Admission to trauma services predicts higher rate of } \\
\text { complications, probably due to more aggressive } \\
\text { treatments }\end{array}$ \\
\hline de Jongh et al. 2011 (25) & The Netherlands & Analyzing records of complications in a trauma registry & $\begin{array}{l}\text { Complications are associated with institution, } \\
\text { diagnosis and injury severity }\end{array}$ \\
\hline Yeung et al. $2012(27)$ & USA & $\begin{array}{l}\text { Comparison of } 81 \text { trauma patients with pneumonia } \\
\text { with a control group }\end{array}$ & $\begin{array}{l}\text { Larger initial gastric volumes at the time of trauma } \\
\text { predicts pneumonia }\end{array}$ \\
\hline Adams et al. $2012(22)$ & USA & $\begin{array}{l}\text { Analyzing data from a trauma registry of a level } 1 \\
\text { trauma center }\end{array}$ & $\begin{array}{l}\text { Older age predicts higher rates of mortality, organ } \\
\text { failure and thrombo-embolic complications }\end{array}$ \\
\hline Kahl et al. 2013 (26) & USA & Analyzing data from a Level 1 trauma center & $\begin{array}{l}\text { Pre-existing medical conditions plays an important role } \\
\text { towards increasing Mortality rate }\end{array}$ \\
\hline Dewar et al. 2013 (14) & Australia & $\begin{array}{l}\text { Prospective study of patients admitted to an ICU in a } \\
\text { level } 1 \text { trauma center }\end{array}$ & Older age and low platelet count predicts MOF \\
\hline
\end{tabular}

tant research topic is the prevention and management of complications in elderly trauma patients with comorbidities (26).

\subsection{Limitations}

In this study, we focused on the acute complications of trauma and hence the chronic consequences of trauma such as disability and psychological sequel were not covered by this review. We did not directly explore the financial burden of the consequences of trauma.

Complications of trauma-related injuries are significant considerations for clinical practice and research.

\section{Acknowledgments}

This study has been funded by the motor accident authority (MAA) NEW South Wales (NSW), Australia. The funder had no role in study design, data collection and analysis, decision to publish, or preparation of the manuscript.

\section{Footnotes}

Authors' Contribution: Pooria Sarrami and Rafael Ekmejian have undertaken the search, all authors have made substantial contributions to this manuscript.

Financial Disclosure: All authors confirmed having no conflicts of interest.

Funding/Support: This study has been funded by the motor accident authority (MAA) New South Wales (NSW), Australia.

\section{References}

1. Connelly LB, Supangan R. The economic costs of road traffic crashes: Australia, states and territories. Accid Anal Prev. 2006;38(6):1087-93. doi: 10.1016/j.aap.2006.04.015. [PubMed: 16797462].

2. Ang DN, Rivara FP, Nathens A, Jurkovich GJ, Maier RV, Wang $\mathrm{J}$, et al. Complication rates among trauma centers. J Am Coll Surg. 2009;209(5):595-602. doi: 10.1016/j.jamcollsurg.2009.08.003. [PubMed: 19854399].

3. Haider AH, Gupta S, Zogg CK, Kisat MT, Schupper A, Efron DT, et al. Beyond incidence: Costs of complications in trauma and what it means for those who pay. Surgery. 2015;158(1):96-103. doi: 10.1016/j.surg.2015.02.015. [PubMed: 25900034].

4. Saltzherr TP, Visser A, Ponsen KJ, Luitse JS, Goslings JC. Complications in multitrauma patients in a Dutch level 1 trauma center. J Trauma. 2010;69(5):1143-6. doi: 10.1097/TA.0b013e3181cb85bb. [PubMed: 20400919].

5. Arksey H, O'Malley L. Scoping studies: towards a methodological framework. Int J Soc Res Methodol. 2005;8(1):19-32. doi: 10.1080/1364557032000119616.

6. Levac D, Colquhoun H, O'Brien KK. Scoping studies: advancing the methodology. Implement Sci. 2010;5:69. doi: 10.1186/1748-5908-5-69. [PubMed: 20854677].

7. Sarrami-Foroushani P, Travaglia J, Debono D, Clay-Williams R, Braithwaite J. Scoping meta-review: introducing a new methodology. Clin Transl Sci. 2015;8(1):77-81. doi: 10.1111/cts.12188. [PubMed: 25041546].

8. Schloman BF. Mapping the literature of allied health: project overview. Bull Med Libr Assoc. 1997;85(3):271-7. [PubMed: 9285127].

9. Ding Y, Chowdhury GG, Foo S. Bibliometric cartography of information retrieval research by using co-word analysis. Inf Process Manage. 2001;37(6):817-42. doi: 10.1016/s0306-4573(00)00051-0.

10. Haas B, Gomez D, Hemmila MR, Nathens AB. Prevention of complications and successful rescue of patients with serious complications: characteristics of high-performing trauma centers. $J$ Trauma. 2011;70(3):575-82. doi: 10.1097/TA.0b013e31820e75a9. [PubMed: 21610345].

11. Osler T, Glance LG, Hosmer DW. Complication-associated mortality following trauma: a population-based observational study. Arch Surg. 2012;147(2):152-8. doi: 10.1001/archsurg.2011.888. [PubMed: 22351910]. 
12. Benns M, Carr B, Kallan MJ, Sims CA. Benchmarking the incidence of organ failure after injury at trauma centers and nontrauma centers in the United States. J Trauma Acute Care Surg. 2013;75(3):426-31. doi: 10.1097/TA.ob013e31829cfa19. [PubMed: 24089112].

13. Dewar DC, Mackay P, Balogh Z. Epidemiology of post-injury multiple organ failure in an Australian trauma system. ANZ J Surg. 2009;79(6):431-6. doi: 10.1111/j.1445-2197.2009.04968.x. [PubMed: 19566865].

14. Dewar DC, Tarrant SM, King KL, Balogh ZJ. Changes in the epidemiology and prediction of multiple-organ failure after injury. J Trauma Acute Care Surg. 2013;74(3):774-9. doi: 10.1097/TA.ob013e31827a6e69. [PubMed: 23425734].

15. Xu SX, Wang L, Zhou GJ, Zhang M, Gan JX. Risk factors and clinical significance of trauma-induced coagulopathy in ICU patients with severe trauma. Eur J Emerg Med. 2013;20(4):286-90. doi: 10.1097/MEJ.ob013e328358bec7. [PubMed: 22976461].

16. Vogel JA, Liao MM, Hopkins E, Seleno N, Byyny RL, Moore EE, et al. Prediction of postinjury multiple-organ failure in the emergency department: development of the Denver Emergency Department Trauma Organ Failure score. J Trauma Acute Care Surg. 2014;76(1):140-5. doi: 10.1097/TA.ob013e3182a99da4. [PubMed: 24368369].

17. Moore L, Stelfox HT, Turgeon AF, Nathens AB, Le Sage N, Emond M, et al. Rates, patterns, and determinants of unplanned readmission after traumatic injury: a multicenter cohort study. Ann Surg. 2014;259(2):374-80. doi: 10.1097/SLA.0b013e31828bofae. [PubMed: 23478531].

18. Fakhry SM, Leon S, Derderian C, Al-Harakeh H, Ferguson PL. Intensive care unit bounce back in trauma patients: an analysis of unplanned returns to the intensive care unit. J Trauma Acute Care Surg. 2013;74(6):1528-33. doi: 10.1097/TA.0b013e31829247e7. [PubMed: 23694883].

19. Hyllienmark P, Brattstrom O, Larsson E, Martling CR, Petersson J, Oldner A. High incidence of post-injury pneumonia in intensive caretreated trauma patients. Acta Anaesthesiol Scand. 2013;57(7):848-54. doi: 10.1111/aas.12111. [PubMed: 23550742].
20. Holbrook TL, Hoyt DB, Anderson JP. The impact of major in-hospital complications on functional outcome and quality of life after trauma. J Trauma. 2001;50(1):91-5. [PubMed: 11231676].

21. Fraser DR, Dombrovskiy VY, Vogel TR. Infectious complications after vehicular trauma in the United States. Surg Infect (Larchmt). 2011;12(4):291-6. doi: 10.1089/sur.2010.081. [PubMed: 21815814].

22. Adams SD, Cotton BA, McGuire MF, Dipasupil E, Podbielski JM, Zaharia A, et al. Unique pattern of complications in elderly trauma patients at a Level I trauma center. J Trauma Acute Care Surg. 2012;72(1):112-8. doi: 10.1097/TA.0b013e318241f073. [PubMed: 22310124].

23. Access Economics . The economic cost of spinal cord injury and traumatic brain injury in Australia. Australia: Access Economics; 2009.

24. Harris AM, Althausen PL, Kellam J, Bosse MJ, Castillo R, Lower Extremity Assessment Project Study G. Complications following limbthreatening lower extremity trauma. J Orthop Trauma. 2009;23(1):1-6. doi: 10.1097/BOT.0b013e31818e43dd. [PubMed: 19104297].

25. de Jongh MA, Bosma E, Verhofstad MH, Leenen LP. Prediction models for complications in trauma patients. BrJ Surg. 2011;98(6):790-6. doi: 10.1002/bjs.7436. [PubMed: 21462365].

26. Kahl JE, Calvo RY, Sise MJ, Sise CB, Thorndike JF, Shackford SR. The changing nature of death on the trauma service. J Trauma Acute Care Surg. 2013;75(2):195-201. doi: 10.1097/TA.0b013e3182997865. [PubMed: 23823614].

27. Yeung L, Miraflor E, Strumwasser A, Sadeghi P, Victorino GP. Does gastric volume in trauma patients identify a population at risk for developing pneumonia and poor outcomes?.J Surg Res. 2012;178(2):874-8. doi: 10.1016/j.jss.2012.07.067. [PubMed: 22917669].

28. Zarzaur BL, Bell TM, Croce MA, Fabian TC. Geographic variation in susceptibility to ventilator-associated pneumonia after traumatic injury. I Trauma Acute Care Surg. 2013;75(2):234-40. doi: 10.1097/TA.ob013e3182924c18. [PubMed: 23823609].

29. Australian Bureau of Statistics . National Health Survey: Injuries, Australia Australia: Australian Bureau of Statistics; 2001. [updated 2003]. Available from: http://www.abs.gov.au/ausstats/abs@.nsf/mf/http:// www.abs.gov.au/ausstats/abs. 